\title{
Itinerario cultural: Lucena, de agrociudad a ciudad media
}

Pilar Zafra Costán, Gema Carrera Díaz, Aniceto Delgado Méndez. Centro de Documentación del IAPH

\author{
Lucena rompe con el \\ modelo de ciudad \\ media valorado \\ positivamente por el \\ POTA a consecuencia \\ de su desarrollo \\ urbanístico e \\ industrial
}

\begin{abstract}
Las tierras llanas y fértiles que circundan la comarca histórico-cultural de la Subbética dibujan el paisaje de la campiña sur cordobesa, entre cuyos límites se encuentra la ciudad de Lucena: horizontes abiertos y leves ondulaciones recortados por la vertical que perfilan las estribaciones de la serranía, donde alternan los cultivos de la trilogía mediterránea -trigo, vid, olivo- y predominan los latifundios. Conforman la identidad de estas tierras, poblaciones de dilatada trayectoria histórica Lucena, Priego de Córdoba, Cabra...- que ejemplifican el tipo de asentamiento que más y mejor singulariza al sistema urbano andaluz: las históricas agrociudades, actuales ciudades medias andaluzas.
\end{abstract}

Definidas por su estrecha vinculación con las fértiles tierras donde se emplazan y por su rica productividad agrícola, estas ciudades, de extensos términos, han jugado históricamente un papel determinante en la articulación del territorio, alcanzando altas cotas de centralidad, y generado, en muchos casos, la dependencia funcional de los municipios circundantes, que han visto a estas ciudades como importantes referencias urbanas. Como apunta J.L Díaz Quidiello en la introducción de la sección (pp. 44-53), estos nodos medulares del territorio han constituido una realidad singular del sistema urbano andaluz, en la que confluyen factores tan antagónicos como sus altas dimensiones poblacionales a modo de ciudad, y una economía históricamente vinculada a la agricultura a modo de centro rural. Entre sus atributos destaca la presencia de una estructura social polarizada, consecuencia del factor que mejor logra definir la agrociudad: la consolidación de un sistema productivo basado en la gran propiedad agraria asociada a la explotación de grandes masas de jornaleros sin tierras; un fenómeno de igual modo característico del sur peninsular: el latifundismo. Sea como fuere, y aunque con el transcurrir del tiempo se han superado sustancialmente parte de estas condiciones sociales y económicas, derogando incluso el término agrociudad por el de ciudad media, la persistencia de estos asentamientos humanos, determinados por su singularidad y por una forma de organización del territorio consolidada ya desde hace siglos, ha demostrado históricamente su eficacia. En esta línea, el Plan de Ordenación del Territorio de Andalucía ha considerado como una de sus principales bazas en el desarrollo equilibrado y sostenible 


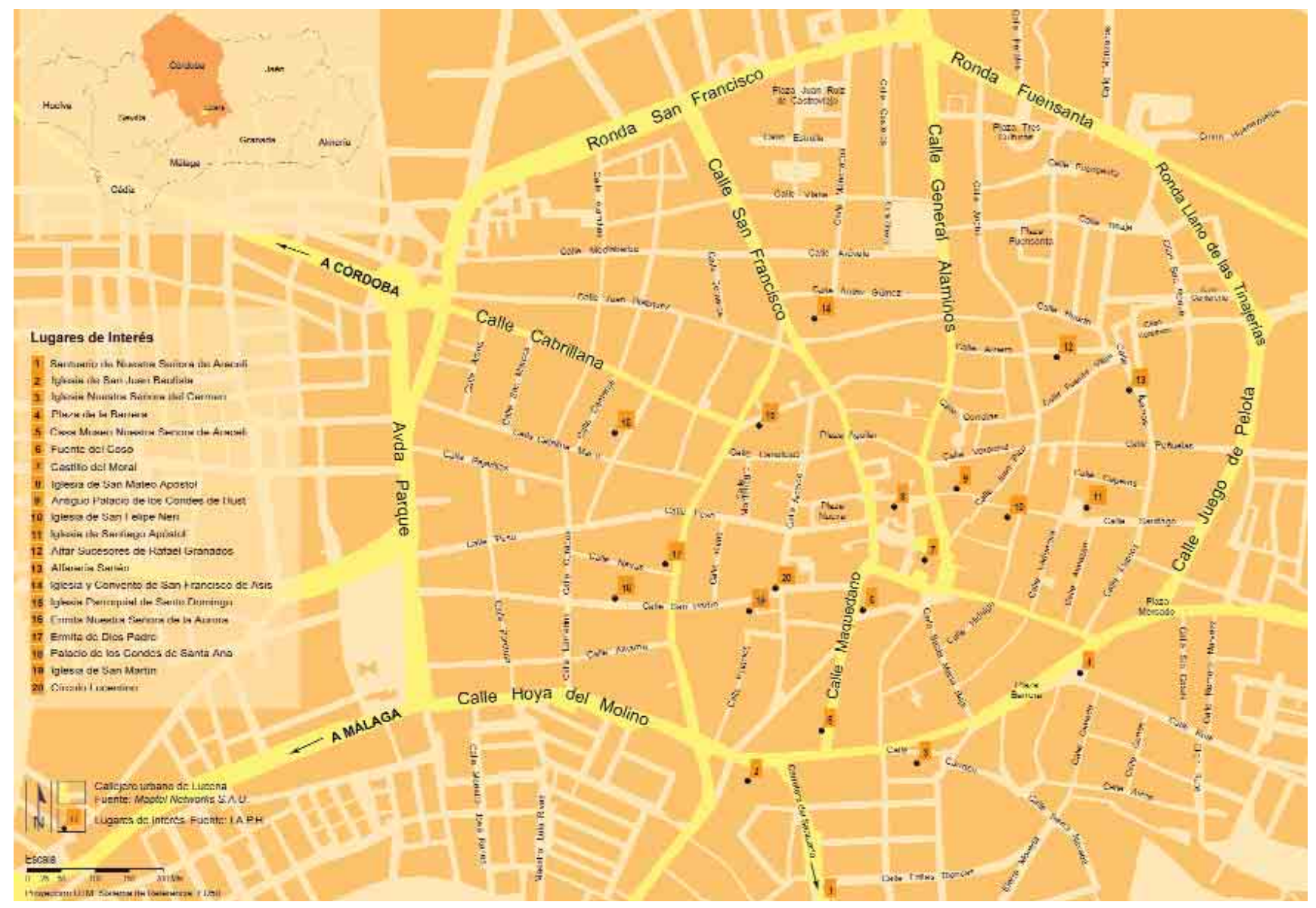

(1) Mapa de itinerario: Lucena al paso / José MANUEL Díaz IGLESIAS, IAPH 


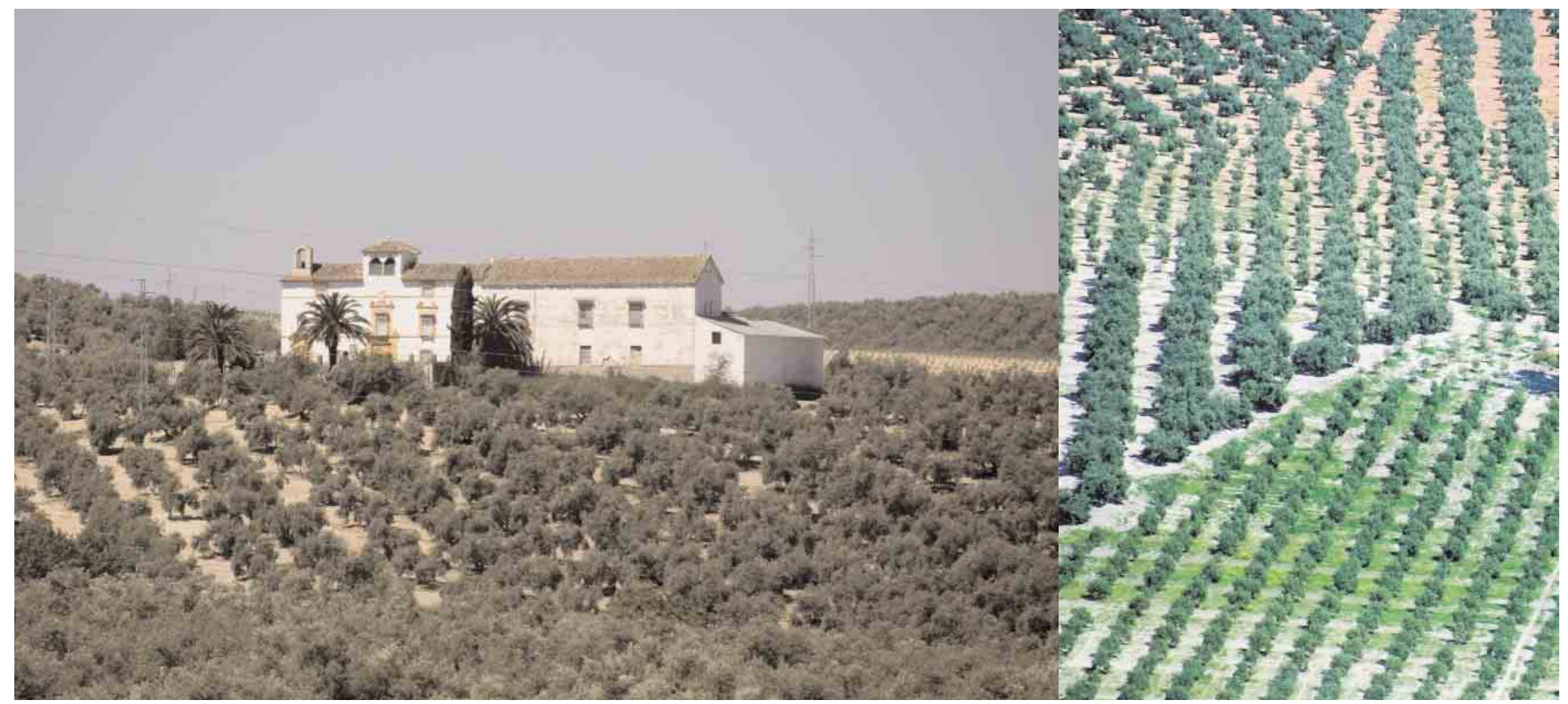

(1) Cortijo Capilla de los Corteses, Lucena (Córdoba) / Aniceto Delgado MÉndez, IAPH

(1) Campo de olivares, Lucena (Córdoba)

Aniceto Delgado MÉndez, IAPH 


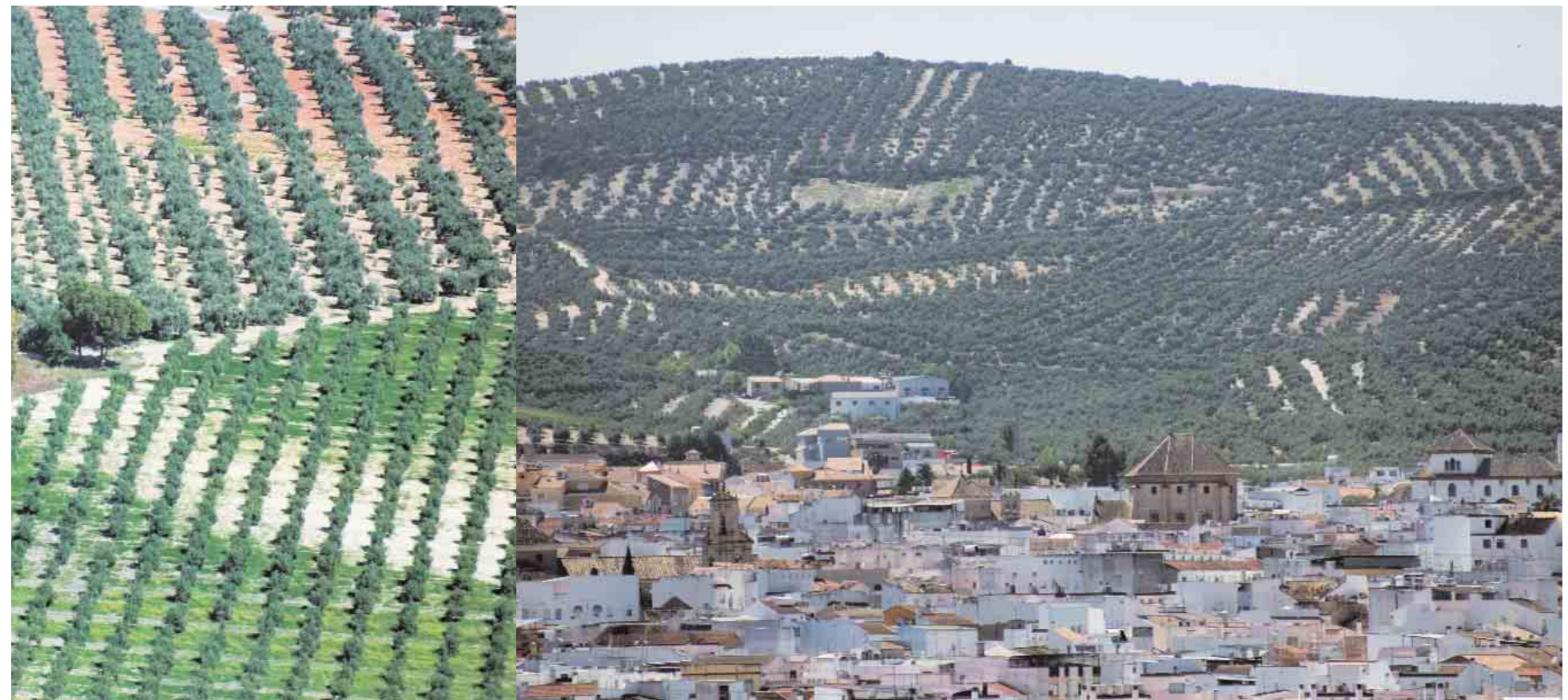

(1) Panorámica de la ciudad de Lucena (Córdoba) / Aniceto Delgado Méndez, IAPH

de Andalucía el aprovechamiento de las potencialidades que ofrecen estas ciudades medias por su interés patrimonial como ciudad en sí, ya que muchas de ellas no sufrieron las grandes transformaciones que trajo consigo el desarrollismo de mediados del XX; por e modelo urbano que aportan, en tanto han sabido mantener su morfología y tipología urbana tradicional; y por su importancia como patrimonio territorial, dada su capacidad para articular el territorio en tanto cabeceras comarcales.

Difícilmente se encontrará en Andalucía una provincia donde la agrociudad-ciudad media alcance una presencia tan contundente como en Córdoba, aspecto que salta plásticamente a la vista cuando se recorren las carreteras que la cruzan engarzando una agrociudad con otra, circundadas de olivares, viñas y numerosos cortijos, haciendas o lagares, y jalonadas por majestuosos castillos que reflejan la evolución de estos asentamientos históricos. Inserta en este marco, la ciudad de
Lucena se perfila como referente que escapa al esquema clásico de las agrociudades del interior de Andalucía, a pesar de haber sido seleccionada como eje central del Plan Turístico Ciudades Medias del Centro de Andalucía (Antequera, Alcalá la Real, Lucena, Loja, Écija, Estepa). Su no coincidencia con el modelo de ciudad media antes definido (Quidiello) viene determinado entre otros factores por su reciente explosión industrial y por la fiebre constructiva que a partir de la década de los 70 del siglo XX generó un imparable proceso de transformación del casco urbano y de destrucción del patrimonio arquitectónico y urbano lucentino' que ha revertido en la pérdida de su identidad histórica. Sin embargo, que duda cabe, y aunque la sombra de su febril desarrollo industrial planea sobre la ciudad, los pocos, aunque excepcionales, testimonios patrimoniales que todavía jalonan su caserío evidencian el significativo papel que Lucena tuvo en el devenir urbano, social y político de Andalucía, y su importancia en la organización territorial de la región, vinculada a la centralidad geopolítica, productiva, comercial y administrativa que ejerció a lo largo de su historia. Las huellas de un pasado prolijo y un presente afanoso dan forma a una urbe hecha y deshecha a sí mima que abraza y rechaza, a un tiempo, la fértil tierra que la alumbró.

Aunque en su término existen indicios de la presencia de asentamientos humanos desde el Paleolítico y son numerosos los hallazgos que testimonian la romanización de estas tierras, las primeras fuentes documentales que dan fe de la existencia de Lucena y evidencian su papel en la historia regional se remontan al periodo de dominación musulmana. La mítica Al Yusanna fue una población de gran relevancia integrada administrativamente durante el Califato en la Cora de Cabra y, en el siglo XI, dentro del Reino Zirí de Granada hasta la conquista almorávide, periodo de gran esplendor económico y cultural, promovido por la rica y extensa comunidad sefardí lucentina. Su espíritu emprendedor influyó decisivamente en el 
desarrollo de la ciudad, que tenía como enseña de su economía el comercio -aceite, vinos, esclavos y eunucos, sedas de Oriente-, haciendo de igual modo notable su presencia en determinados sectores de la administración estatal, en el sector servicios y en la industria, consolidándose ya en esta época una incipiente industria artesanal vinculada al trabajo del metal -bronce y cobre- contribuyendo a convertir a la ciudad en el principal enclave español en la artesanía de los metales. Considerada como la ciudad de la poesía y denominada por los judíos como La Perla de Sefarad, se cultivaron en su Academia de Estudios Talmúdicos personajes relevantes de la época, ejerciendo sus rabinos un importante magisterio religioso entre las comunidades judías del occidente europeo hasta la invasión almohade, en 1 148, periodo en que la población tuvo que emigrar a los reinos cristianos del norte. Tomada en 1240 por Fernando III de Castilla, el papel de los señores de Lucena resultó crucial durante la Conquista Cristiana, pues fue durante siglos una ciudad fronteriza hasta que en la célebre batalla del arroyo de Martín González se derrotó al último rey de Granada, Boabdil, el Chico, que pasó sus últimos días preso en la Torre del Castillo del Moral. Este proceso de conquista fue traumático para la ciudad de Lucena, porque trajo consigo la expulsión de árabes y judíos, y con ellos la pérdida de todo su bagaje cultural, económico, social y una importante regresión demográfica que condujo a la concentración de la población dentro de los muros de la incipiente ciudad cristiana. Posteriormente, las diversas elites político-económicas y las autoridades eclesiásticas que se sucedieron, animados por la euforia económica y mercantil que caracterizó fundamentalmente al siglo XVIII, mostraron e hicieron alarde de su poder a través de las construcciones públicas, civiles, eclesiásticas y militares que costearon, convirtiendo a Lucena en uno de los emporios barrocos por excelencia. La irrupción del siglo XIX hará gala del pensamiento ilustrado en la renovación de la fisonomía urbana y constituirá el germen de una variada industria que posibilitará el aumento demográfico, iniciando un rápido desarrollo económico que florecerá en el siglo XX, convirtiendo a Lucena, tanto a nivel provincial como regional, en la segunda ciudad tras Córdoba capital con el mayor potencial de crecimiento a todos los niveles, conformando lo que hoy constituye uno de los centros con mayor empuje en el sector industrial y el sector servicios de Andalucía (metales, líquidos, aceites, mueble, etc.). Vertebran el siguiente recorrido elementos del patrimonio cultural lucentino que reflejan parte de este devenir histórico y presente descrito, representando y convirtiéndose en señas de identidad de esta ciudad media y, por ende, de la comarca que articula.

\section{Lucena, al paso}

El vagabundo, antes de entrar en Lucena, prefirió verla -en compañía de todo lo que desde allí se ve-, subido al santuario de Araceli, la atalaya de uno de los más bellos paisajes españoles. El vagabundo, desde su alto mirador, se sintió poderoso como nunca y también vagamente feliz. El andar por los caminos brinda, de vez en vez, gozos que no podrían comprarse con dinero. ${ }^{3}$

Un horizonte de olivos anuncia la llegada a las ricas tierras enclavadas entre la feraz campiña y las primeras estribaciones de la Subbética cordobesa, presididas por la Sierra de Aras, a seis kilómetros de Lucena, en cuya cima se perfila el Santuario de Nuestra Señora de Araceli, punto de partida de este recorrido. Elevada en un altar clavado en el centro geográfico de Andalucía, cinco provincias -Córdoba, Jaén, Granada, Málaga, Cádiz y Sevilla- y más de una treintena de pueblos parecen ofrecer sus frutos a la Patrona del Campo Andaluz. Foco de una de las romerías más renombradas de Córdoba y monumental templo de la devoción y el arte más puramente barroco, su emplazamiento es testigo de las numerosas construcciones, erigidas en su mayoría entre los siglos XVIII y XIX por las elites locales, que salpican el paisaje subrayando la presencia de grandes explotaciones agrícolas": haciendas de olivar, cortijos y lagares; arquitecturas que personifican el pasado y presente agrario de Lucena y 


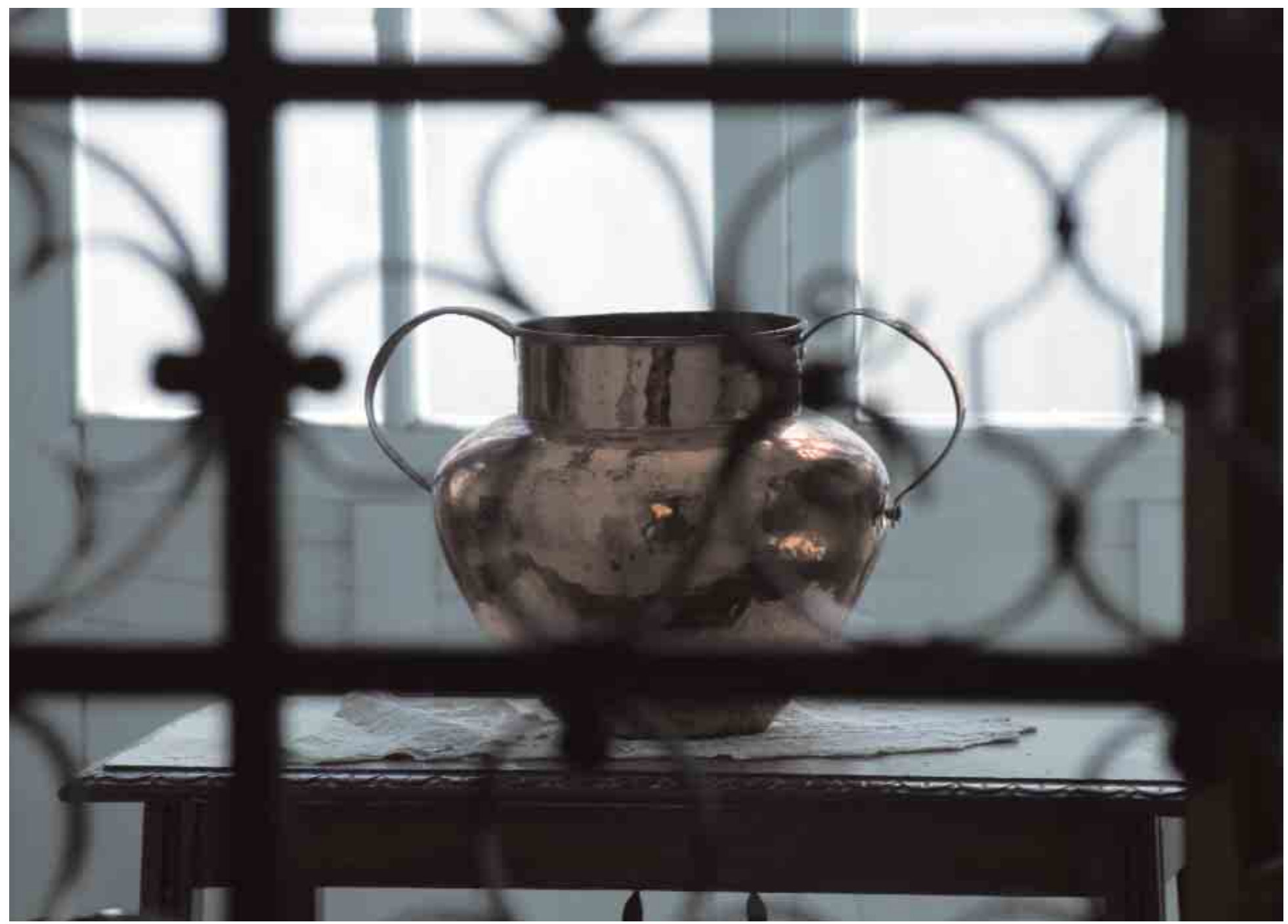

(๑) Trabajo del cobre en una vivienda de Lucena / ANICETo DeLGAdo MÉndeZ, IAPH 


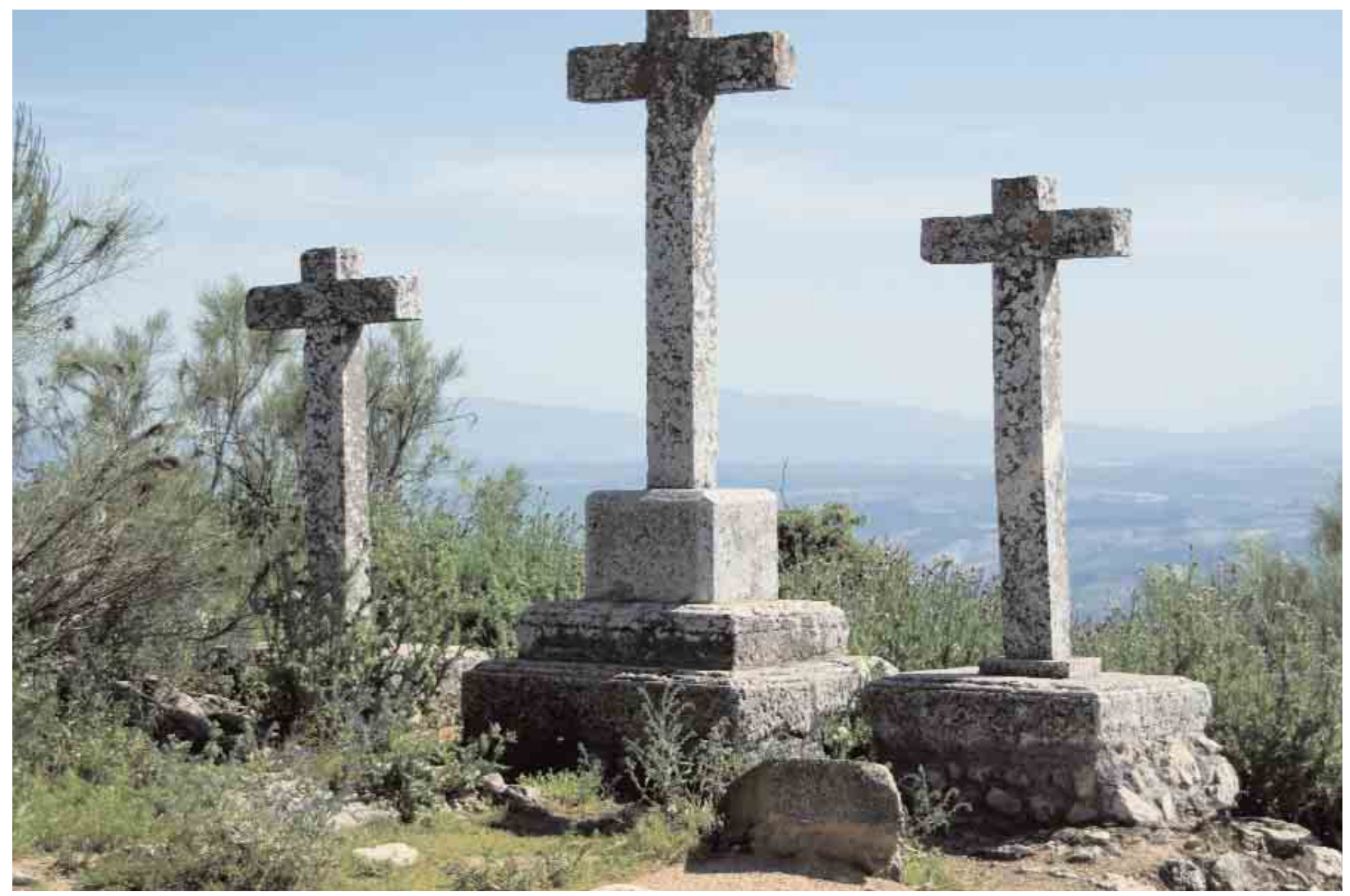

(1) Santuario de Nuestra Señora de Araceli. Detalle Calvario / Aniceto Delgado MÉndez, IAPH

cuya intencionalidad compositiva supera lo puramente funcional constituyendo uno de los capítulos más significativos y menos conocidos del patrimonio cultural de su término.

Lucena se define a lo lejos. El espíritu hacendoso de la ciudad sale repentinamente al encuentro, con multitud de naves industriales que jalonan su término, herederas fabriles de actividades tan pujantes en otros tiempos como su renombrada producción vinícola, representada por una nutrida nómina de bodegas, de la que prácticamente no quedan testimonios (Torre Burgos, Mora Chacón, Aragón y Cía...); los oficios artesanos del metal, encumbrados por el velón, principal producto local y referente de la ciudad, a los que ha ganado la batalla la producción en serie; y los oficios derivados del empleo del barro, aplicados a la producción de objetos como las orzas, botijas, platos, tinajas, o la perula, pieza local más importante empleada para almacenar aceite, el preciado oro. Su representación en la actualidad se reduce, si cabe, a la toponimia de calles como La Tinaja, Alfarería o Cantarería, agrupadas en torno al
Parque Llano de las Tinajerías en el que tan sólo perduran dos de los más de cuarenta alfares $^{5}$ que existían. Hoy la presencia de la industria desdibuja la impronta urbana de la ciudad histórica que antaño reducía la necesidad de interpretación a dos sencillos planos: el horizontal de tejas morunas y paredes enjalbegadas y el vertical de sus espadañas barrocas, sus docenas de iglesias y conventos y las torres de un castillo que evoca tiempos de mayor esplendor.

La llegada a Lucena desde el Santuario parece anunciar el empaque de su legado cultural con la presencia de la Iglesia de Nuestra Señora del Carmen, enclavada en un altozano sobre el barrio de La Barrera, de gran tradición flamenca, y la Iglesia de San Juan Bautista con su hospital anejo, conocida como San Juan de Dios; dos soberbios ejemplos de la importancia de las ordenes religiosas durante la Edad Moderna, que convirtieron a Lucena en una ciudad conventual. La primera fue construida por la orden de Carmelitas Descalzos hacia 1630, siguiendo las pautas artísticas carmelitanas dentro de un severo estilo barroco 


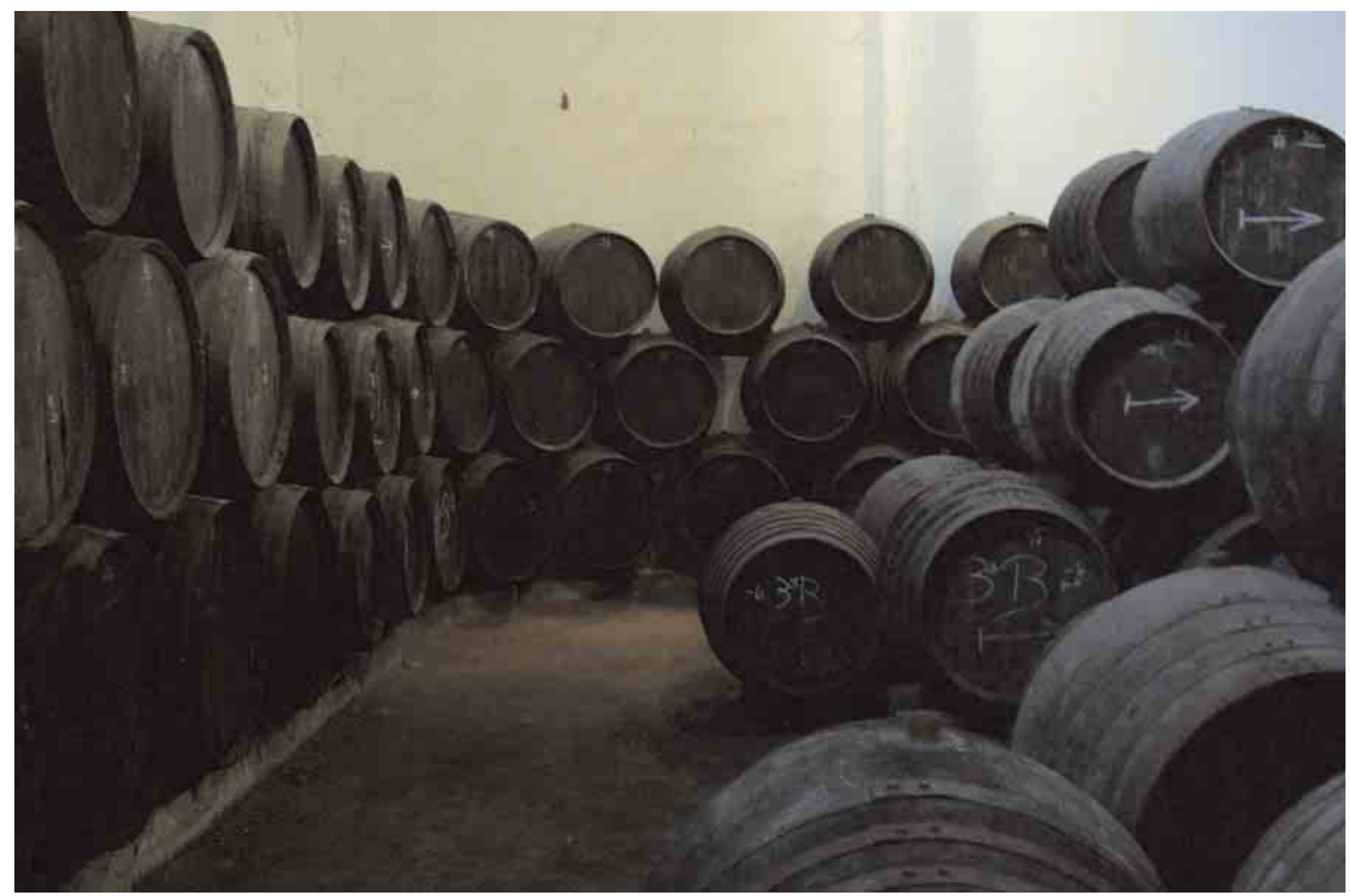

(1) Interior Bodegas Aragón y Cía. / Aniceto Delgado MÉndez, IAPH

purista. La segunda, ejemplar singular del barroco lucentino, fue erigida por la Orden Hospitalaria de San Juan Bautista en 1755, destacando en su factura la portada de la iglesia, a modo de retablo, realizada en mármoles policromos y enriquecida con labores de embutidos, y la sobria fachada del centro hospitalario. Ambas conforman uno de los frentes de la Plaza de la Calzada o de San Juan de Dios, personalizando su ámbito urbano.

Sin embargo, el centro neurálgico lucentino se concentra en torno al Castillo del Moral y la antigua Plaza de Armas, el Coso -hoy Plaza de España-. La fortaleza es heredera de la musulmana del siglo XI y muestra aún dos torres medievales, una octogonal, modificada en el siglo XVIII para conformar la residencia palaciega de los señores de Lucena, y otra rectangular donde estuvo preso Boabdil el Chico, que actualmente alberga la Oficina de Turismo y el Museo Arqueológico y Etnográfico. Desde el castillo, a tan sólo un paso, Lucena se rinde al más puro Barroco. La iglesia parroquial de San Mateo, "la Catedral de la Subbética", constituye un buen ejemplo de transición entre el Gótico y el Renacimiento andaluz, encumbrado por el excelente retablo manierista que ocupa el altar mayor. Sin embargo, su interior alberga uno de los testimonios que, junto al Santuario de Nuestra Señora de Araceli, constituye una de las mejores muestras del barroco cordobés: la capilla del Sagrario. Realizada entre 1740 y 1772 y enmarcada por una prodigiosa portada realizada con mármoles policromos de la comarca, el interior de la capilla muestra un apabullante despliegue ornamental. Las labores de yeso tallado imprimen una sensación de movimiento continuo de luces y sombras, encuadrando un programa pictórico alusivo al triunfo de la Iglesia y la defensa de la Eucaristía.

La fachada principal del templo se asoma a la Plaza Nueva, el centro de la vida social lucentina. Desde aquí todo son opciones. Junto a los numerosos ejemplos de arquitectura monacal como el Convento Madre de Dios, de sobria factura manierista y conocido popularmente como Los Franciscanos, el de Santo Domingo, hoy reconvertido en hotel, y templos tan distintivos como el de San Felipe Neri o la Iglesia de Santiago, enclavada en el antiguo arrabal 
$\boldsymbol{\Theta}$ En el torno. Alfar, Sucesores de Rafael Granados /

Aniceto Delgado Méndez, IAPH

(- Cargando el horno. Perulas. Alfarería la Sartén /

Aniceto Delgado Méndez, IAPH
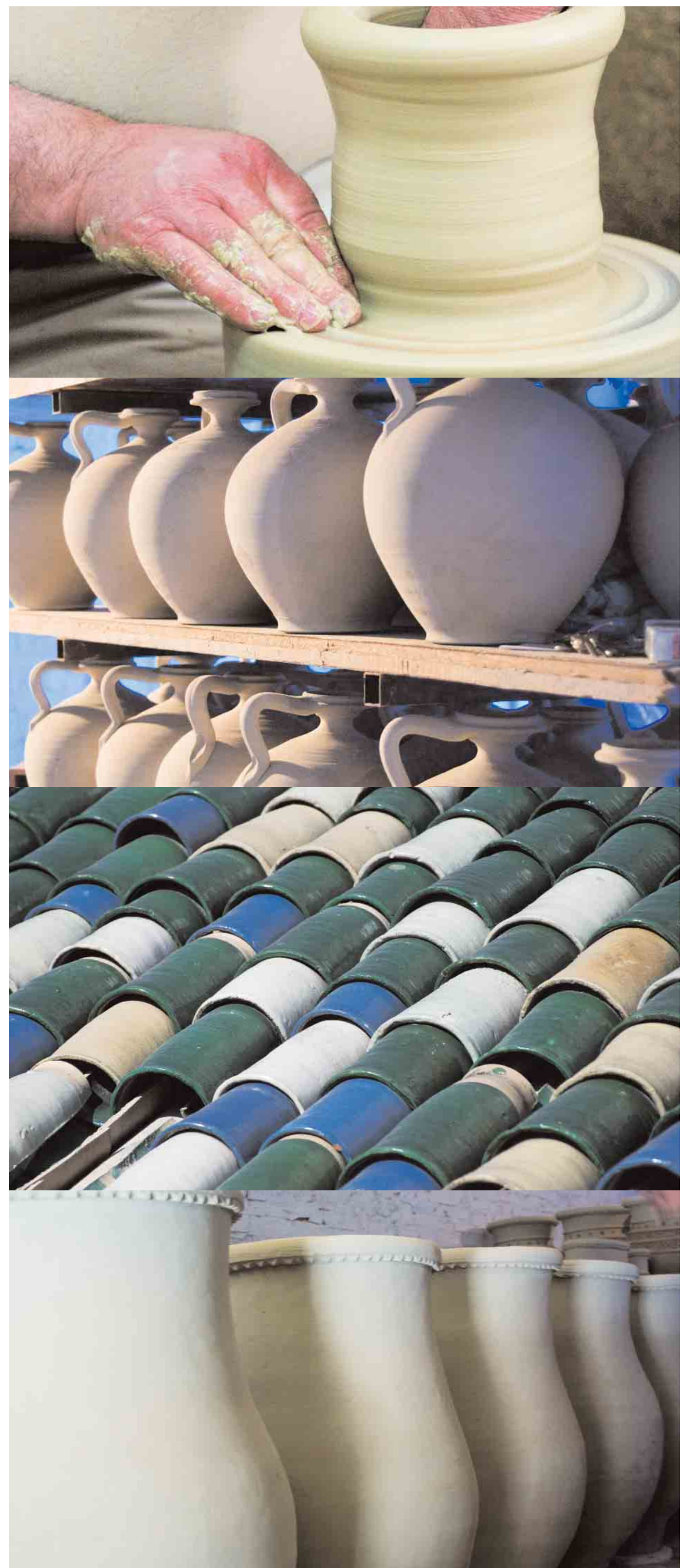

(2) Detalle cubierta taller alfarero. Alfarería la Sartén / Aniceto Delgado Méndez, IAPH 


\section{En la web}

Web del Congreso Andaluz de Ciudades Medias

http://www.cademloja.com/index2.html, celebrado en Loja en marzo de 2007, con motivo del plan piloto puesto en marcha por la Consejería de Turismo, Comercio y Deportes.

Web del Ayuntamiento de Alcalá la Real

http://www.alcalalareal.es/. A través del apartado dedicado a "Turismo" se puede encontrar información de la historia, las tradiciones y fiestas populares asi como de productos artesanales del municipio. En "Qué visitar" se puede acceder a "Rutas turisticas", donde se ofrece información de un Itinerario Cultural Europeo en el que está incluida la ciudad.

Web del Portal del Ayuntamiento de Antequera

http://www.antequera.es/. Es muy completa y tiene una sección dedicada al patrimonio histórico de la ciudad de Antequera, "Ciudad del Arte", además de accesos que contienen información de las fiestas, las ferias, el folclore o la gastronomía, entre otros aspectos.

Web del Ayuntamiento de Écija

http://www.ecija.es/. Esta página permite el acceso al Portal de Turismo de Écija http://www.turismoecija.com/, que es donde realmente se encuentra la información sobre la historia de la ciudad, el patrimonio y sus monumentos, posibles rutas o itinerarios culturales, la artesanía o la gastronomía, entre otros.

Web del Ayuntamiento de Estepa

http://www.estepa.com/, que a través del botón "Ciudad" ofrece información de su historia y su patrimonio arquitectónico asi como de sus fiestas.

Web del Ayuntamiento de Loja

http://www.aytoloja.org/inicio/inicio/inicio.htm, que permite acceder a un apartado muy completo sobre la historia de la ciudad, donde se puede encontrar información de sus monumentos (incluidas ermitas y fuentes, entre otros elementos) y restos arqueológicos. Asimismo, hay una sección sobre el Centro de Interpretación de Loja.

Web del Portal del Ayuntamiento de Lucena

http://www.aytolucena.org/. A través de la sección "La Ciudad" se obtiene información sobre las fiestas populares, el Museo Arqueológico y Etnológico, etc. y se puede acceder a la Oficina de Turismo de Lucena. 


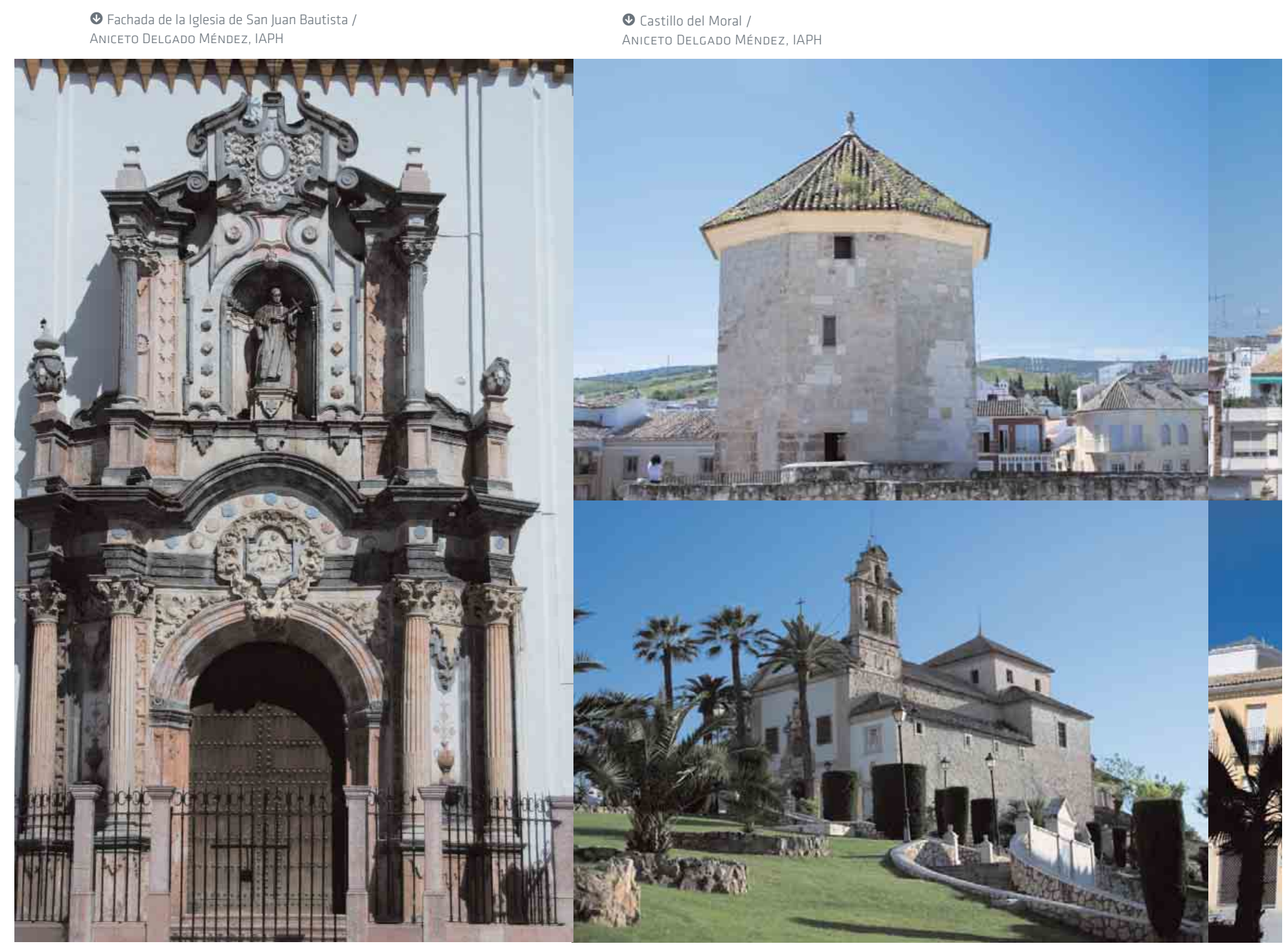

(1) Iglesia de Nuestra Señora del Carmen / Aniceto Delcado MÉndez, IAPH

medieval, jalonan el casco histórico lucentino un sin fin de ermitas, entre cuyos tipos más representativos sobresalen la Ermita de Dios Padre y la de La Aurora. Esta última, de gran devoción popular, cobra especial relevancia en octubre, cuando todo el barrio se llena de castañas asadas y en las madrugadas cantan los campanilleros por las calles.

Durante el itinerario, la mirada se tropezará con docenas de palacios, casas solariegas y alguna muestra del tipo de vivienda de la clase media -de dos plantas más torre- y de arquitectura tradicional que componían el grueso del caserío lucentino. Ejemplos de esto último son el Palacio de los Condes de Santa Ana, edificio del XVIII y actual sede de los Juzgados de Lucena; el Antiguo Palacio de los Condes de Hust, casa solariega de mediados del siglo XVII, situada en una de las calles de la vieja judería; o la Casa de los González Palma.

La visión de la Lucena decimonónica patente en la sede del Círculo Lucentino, en el que se funden sabiamente elementos neoaca- demicistas con la arquitectura del hierro, completa la panorámica por esta ciudad media ya que el siglo XX, aunque ofrece algunas muestras de Modernismo, Regionalismo, Racionalismo y puntuales ejemplares adscritos a los movimientos arquitectónicos internacionales surgidos desde la década de los 70, no reviste gran interés aunque haya que subrayar su presencia.

Lucena al paso nos ha dejado entrever parte de la sombra y del reflejo de esa compleja historia de Andalucía que se 


\section{Bibliografía}

(-) Iglesia de San Mateo y Sagrario /

Aniceto Delgado MÉndez, IAPH

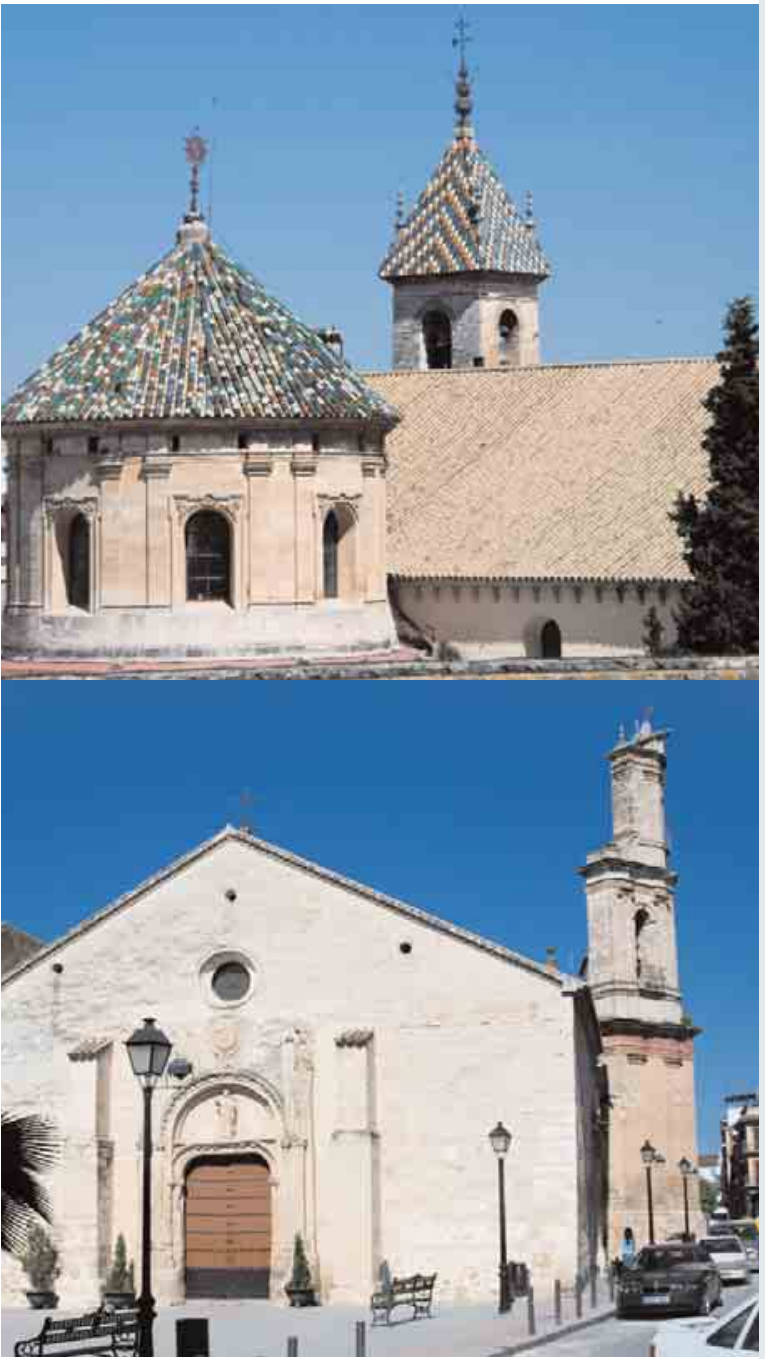

(1) Iglesia de Santiago /

Aniceto Delgado Méndez, IAPH
ANÁLISIS urbanistico de centros históricos de Andalucía : ciudades medias y pequeñas. Sevilla : Consejería de Obras Públicas y Transportes, 2001 *

ANDRÉS LóPEZ, Gonzalo. Crecimiento, forma y funciones de una ciudad media española la estructura urbana de Burgos en los siglos XIX y XX. Tesis doctoral inédita. Universidad de Valladolid, 2003

BIELZA DE ORY, Vicente. Ordenación del territorio y desarrollo comarcal a partir de ciudades medias. En: El desarrollo integral de una comarca en transformación: una perspectiva territorial, empresarial y formativa. Madrid: UNED, 1999, p. 15-30

\section{CIUDADES intermedias y urbanización mundial = Intermediate cities and world} urbanisation. Lleida [etc.] : Ajuntament de Lleida [etc.], 1999 *

CURSO “LAS CIUDADES HISTÓRICAS DEL MEDITERRÁNEO " (2005-2006. Málaga). Las ciudades históricas del Mediterráneo : el sector turístico, la dinamización cultural y las nuevas tecnologías aplicadas al patrimonio cultura. Málaga: Departamento de Historia del Arte de la Universidad de Málaga [etc.], 2006 *

DIAZZ QUIDIELLO, Juan Luis. Las ciudades medias históricas. PH : Boletín del Instituto Andaluz del Patrimonio Histórico, $\mathrm{n}^{\circ}$ 38, marzo 2002, p. 204-209*

ESTUDIO básico sobre ciudades medias. Madrid : Ministerio de Obras Públicas y Urbanismo, 1980, 2 v.

FERRER REGALES, Manuel (coord.). Ecología social y ambiente : las ciudades medias y pequeñas. Pamplona : Universidad de Navarra,1991

GALÁN JIMÉNEZ, María del Mar. La planificación y la gestión del turismo urbano en cuatro ciudades medias andaluzas. En : Anales de economía aplicada, Asociación Española de Economía Aplicada, ASEPELT , 2003

GONZÁLEZ GONZÁLEZ, M. J. La sostenibilidad de los centros históricos en los albores del siglo XXI, Anales de Geografía de la Universidad Complutense, $n^{\circ} 26,2006$, p. 49-63.

HERNÁNDEZ DE LA OBRA, Marta; MILLÁN RINCÓN, Juan. Análisis del espacio público en las ciudades medias de andalucía. [S.I. : Consejería de Política Territorial, 1991]

JORNADAS SOBRE CIUDADES MEDIAS (1990. Baena, Córdoba). Jornadas sobre ciudades medias. Sevilla : Consejería de Obras Públicas y Transportes, 1991 *

JORNADAS SOBRE PLANEAMIENTO URBANISTICO E INTERVENCIÓN EN LA CIUDAD HISTÓRICA (2001. Montoro, Córdoba). La ordenación e intervención urbanística en la ciudad histórica de carácter medio. Sevilla : Consejería de Obras Públicas y Transportes, $2001^{*}$

LABORDE, Pierre. Dinámica de las ciudades medias y su papel de reequilibrio territorial. En : Ciudad y alfoz : centro y periferia urbana : Jornadas de estudio y debate urbanos, Universidad de León, 1996, p. 11-24

LLOP TOMÉ, Josep; BELLET SANFELIU, Carmen. Ciudades intermedias : entre territorios concretos y ciudades y espacios globales. Ciudad y territorio : Estudios territoriales, $\mathrm{n}^{0}$ $141-142,2004$, p. 569-582.

LóPEZ ONTIVEROS, Antonio (coord.). Geografía de Andalucia, Madrid, Ariel, 2003. *

LÓPEZ ONTIVEROS, Antonio. La agrociudad andaluza : Caracterización, estructura y problemática. Revista de Estudios Regionales. Málaga : Universidad de Málaga, Facultad de Ciencias Económicas y Empresariales, $n^{\circ} 39$ (1994), p. 59-93. 
MALLARACH ISERN, Jordi; VILAGRASA Y IBARZ, Joan. Los procesos de desconcentración urbana en las ciudades medias españolas. Ería : revista cuatrimestral de geografía, $\mathrm{n}^{0} 57,2002$, p. 57-70.

PFU: : manual para la elaboración de un prediagnóstico técnico sobre funciones urbanas en ciudades medias : policentrismo a través de la red de ciudades medias (CIUMED). [Valencia] : Dirección General de Planificación y Ordenación Territorial, Servicio de Ordenación Territorial, 2005

PLAN de Ordenación del Territorio de Andalucía : bases y estrategias : Decreto 103/1999, de 4 de mayo. Sevilla : Consejería de Obras Públicas y Transportes, 1999*

PLAN de Ordenación del Territorio de Andalucia : bases y estrategias : Decreto 103/1999, de 4 de mayo. Sevilla : Consejería de Obras Públicas y Transportes, 1999 *

RUIZ JIMÉNEZ, María Angeles. Formas de desarrollo y cooperación desde la cultura y el patrimonio: las ciudades medias de la frontera hispanomarroquí. Los casos de Jerez de la Frontera y Tetuán. En : III Congreso Universidad y Cooperación al Desarrollo : Madrid, 26 28 de abril de 2006 : ponencias y comunicaciones, vol. III, 2006, p. 25-41

SALOM CARRASCO, Julia. Ciudades medias y centros intermedios en el arco mediterráneo. En : Las ciudades españolas a finales del siglo XX : I Coloquio de Ceografía urbana. [Cuenca] : Universidad de Castilla-La Mancha ; [Madrid] : Asociación de Geógrafos Españoles, 1995, p. 53-56.

SEMINARIO Internacional : les ciutats mitjanes en el context regional europeu : ponencies 1994= las ciudades medianas en el contexto regional europeo. Sabadell : l'Ajuntament, DL 1994.

TERRITORIO y patrimonio. Los paisajes andaluces. [Sevilla] : Instituto Andaluz de Patrimonio Histórico ; [Granada] : Comares, 2003 *

VALENZUELA MONTES, Luis Miguel. Accesos y forma urbana en las ciudades medias andaluzas : tesis doctoral. Granada : Universidad de Granada, Escuela Técnica Superior de Ingenieros de Caminos, Canales y Puertos, 2000

VILAGRASA Y IBARZ, Joan; GANAU I CASAS, Joan. Ciudades medias en España: posición en la red urbana y procesos urbanos recientes. Mediterráneo económico, $n^{\circ} 3$, 2003 (Ejemplar dedicado a: Ciudades, arquitectura y espacio urbano, p. 37-73

ZOIDO NARANJO, Florencio. Sistema de asentamientos, ciudades medias y aglomeraciones urbanas de Andalucia. Evolucion reciente. Situación : revista de coyuntura económica, $\mathrm{n}^{\circ} 3,1995, \mathrm{p} .149-162$. 


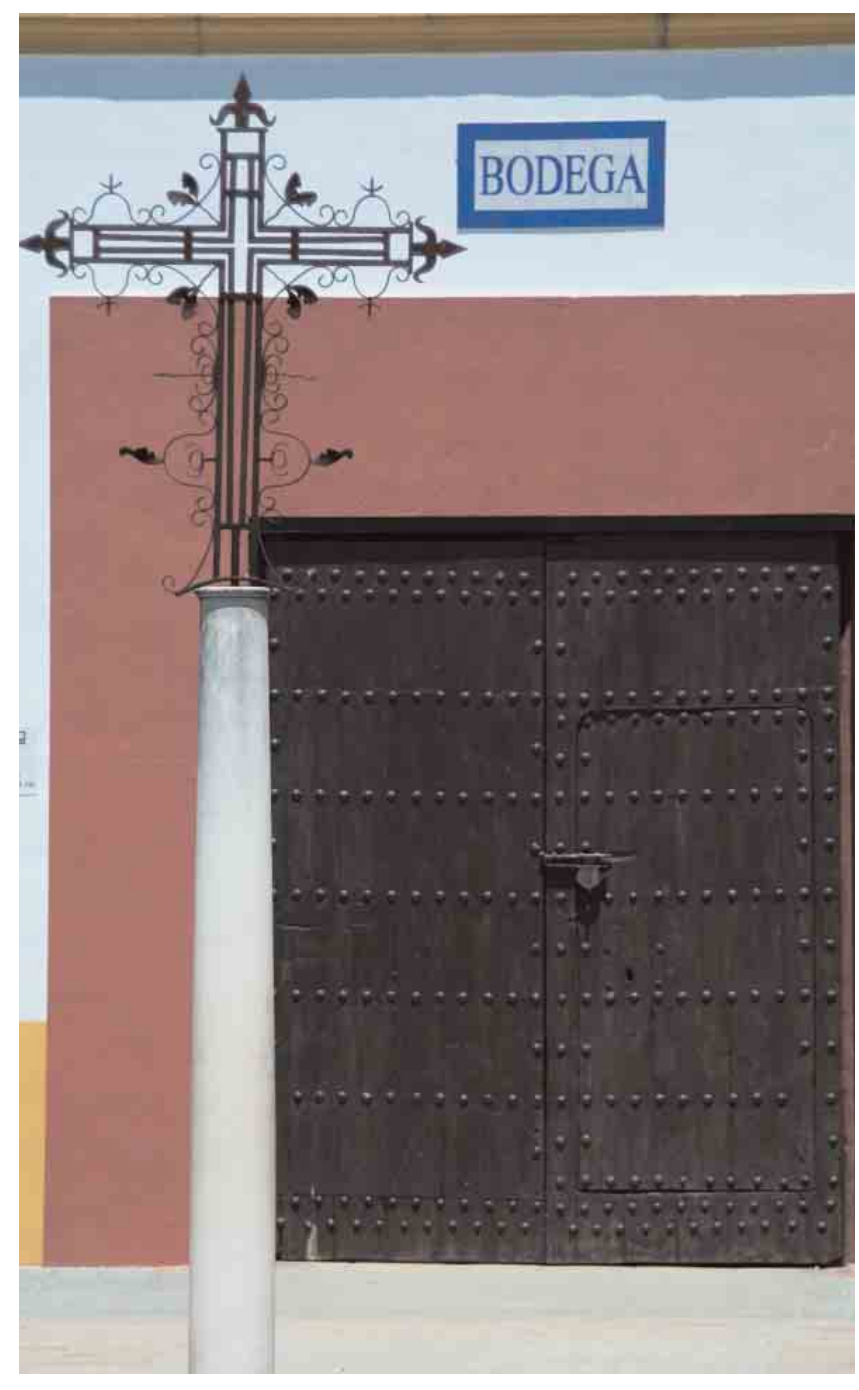

(1) Exterior Bodegas Aragón y Cía. / Aniceto Delgado Méndez, IAPH

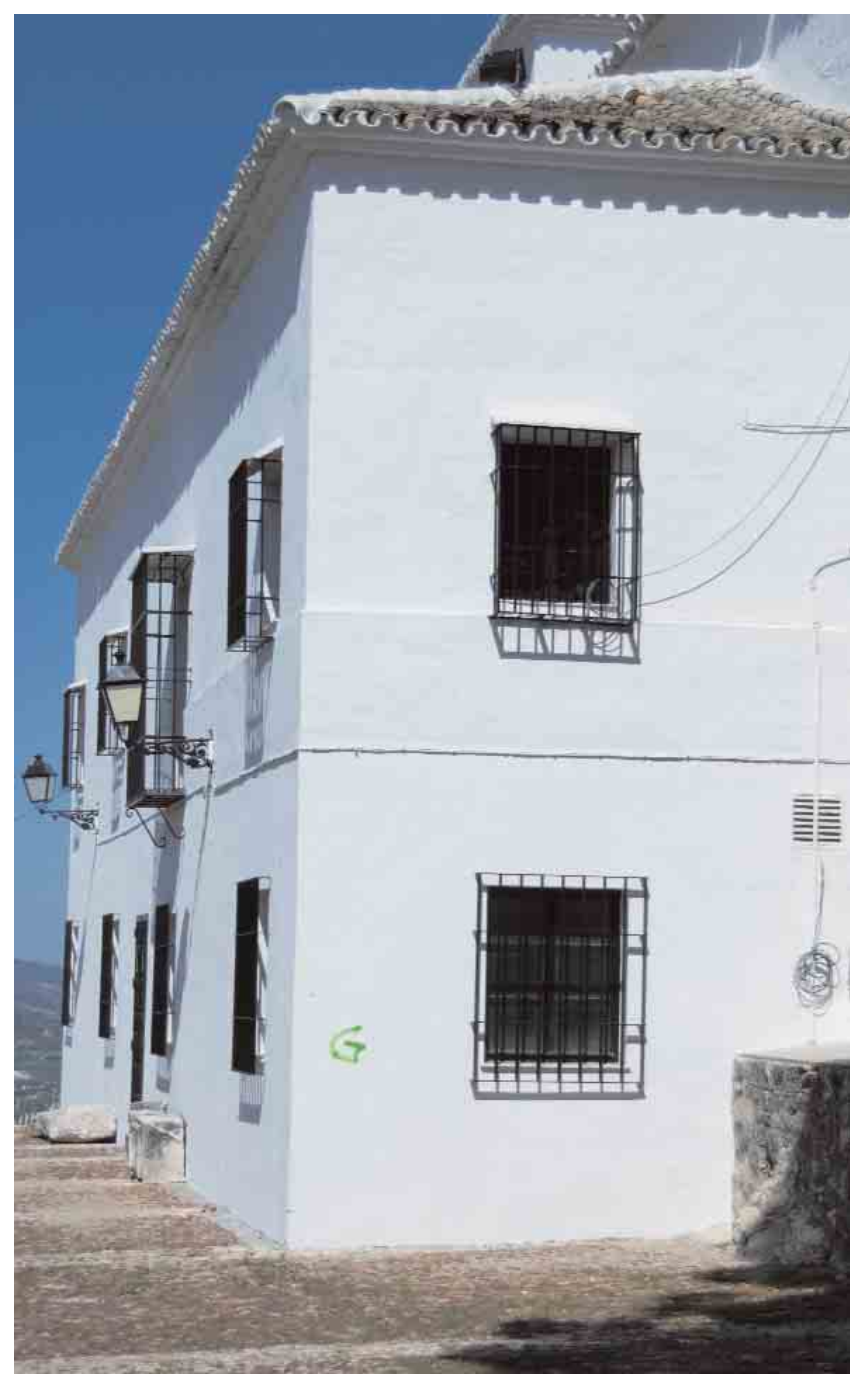

(1) Detalle dependencias auxiliares Santuario de Nuestra Señora de Araceli / aniceto Delgado Méndez, IAPH resuelve en las agrociudades de un modo tan plástico, pudiendo emplear sus entramados urbanos y sus amplios términos como textos históricos y etnográficos útiles para entender el concepto de ciudad media interior. A través de la rica economía lucentina (actividades industriales, artesanales), de lo poco que queda de su arquitectura civil, edificios religiosos, arquitectura defensiva, deteriorado entramado urbano, o en su escasa arquitectura vernácula aún en pie y su desconocida arquitectura diseminada, podemos ver parte de la Historia de esta pequeña gran ciudad media y de su centralidad histórica. Pero podríamos haber visto aún más si en su último devenir contemporáneo se hubieran tenido en cuenta propuestas de actuación más sostenibles. En las últimas décadas, Lucena ha visto cómo se desdibujaban sus viarios y caseríos como consecuencia del desarrollo urbanístico e industrial de los setenta, rompiendo con el modelo de ciudad media de interior estimado por el POTA como un patrimonio cultural y territorial de Andalucía, comportándose más como un centro regional de segundo orden que como una ciudad media de interior tipo. Si miramos lo que fue y lo que es, podemos extraer algunas conclusiones acerca de lo que no debe hacerse en las ciudades medias de interior, y no entender por qué se elige un modelo de actuación patrimonial no modélica como punto central de estrategias turísticas en torno a las mismas.

\section{Notas}

${ }^{1}$ Edificios singulares como los conventos de Santa Clara o el de San José y Santa Teresa, la Posada de Vistahermosa o las Casas de las Pilas serán derruidos durante las décadas de los 70 y 80 del siglo pasado, así como la importante judería, parte crucial de su histórico entramado urbano, de la que no han perdurado testimonios físicos importantes.

${ }^{2}$ Entre otras, la Asociación Cultural Torre del Moral.

${ }^{3}$ Fragmento de la obra de Camilo José Cela Primer viaje andaluz: notas de un vagabundaje: por Jaén, Córdoba, Sevilla, Huelva y sus tierras. (Barcelona: Noger 1959)

${ }^{4}$ Alguno de los testimonios más representativos que se diseminan por su término lo constituyen la Hacienda Lo Coronel, la Casería del Canónigo, el Cortijo Capilla de los Corteses, el Cortijo Lo Angulo, el Cortijo los Frailes o el Molino de las Torres.

${ }^{5}$ Alfarería Sartén y Cerámica Granados. 